\title{
A case study on the formation and evolution of ice supersaturation in the vicinity of a warm conveyor belt's outflow region
}

\author{
P. Spichtinger ${ }^{1}$, K. Gierens ${ }^{1}$, and H. Wernli ${ }^{2}$ \\ ${ }^{1}$ Deutsches Zentrum für Luft- und Raumfahrt, Institut für Physik der Atmosphäre, Oberpfaffenhofen, Germany \\ ${ }^{2}$ Johannes Gutenberg-Universität, Institut für Physik der Atmosphäre, Mainz, Germany
}

Received: 30 July 2004 - Published in Atmos. Chem. Phys. Discuss.: 15 December 2004

Revised: 9 March 2005 - Accepted: 15 March 2005 - Published: 22 March 2005

\begin{abstract}
A case study is presented on the formation and evolution of an ice-supersaturated region (ISSR) that was detected by a radiosonde in NE Germany at 06:00 UTC 29 November 2000. The ISSR was situated in the vicinity of the outflow region of a warm conveyor belt associated with an intense event of cyclogenesis in the eastern North Atlantic. Using ECMWF analyses and trajectory calculations it is determined when the air parcels became supersaturated and later subsaturated again. In the case considered, the state of air parcel supersaturation can last for longer than $24 \mathrm{~h}$. The ISSR was unusually thick: while the mean vertical extension of ISSRs in NE Germany is about $500 \mathrm{~m}$, the one investigated here reached $3 \mathrm{~km}$. The ice-supersaturated region investigated was bordered both vertically and horizontally by strongly subsaturated air. Near the path of the radiosonde the ISSR was probably cloud free, as inferred from METEOSAT infrared images. However, at other locations within the ISSR it is probable that there were cirrus clouds. Relative humidity measurements obtained by the Lindenberg radiosonde are used to correct the negative bias of the ECMWF humidity and to construct two-dimensional maps of ice supersaturation over Europe during the considered period. A systematic backward trajectory analysis for the ISSRs on these maps shows that the ISSR air masses themselves experienced only a moderate upward motion during the previous days, whereas parts of the ISSRs were located just above strongly ascending air masses from the boundary layer. This indicates qualitatively that warm conveyor belts associated with mid-latitude cyclogenesis are disturbances that can induce the formation of ISSRs in the upper troposphere. The ISSR maps also lead us to a new perception of ISSRs as large dynamic regions of supersaturated air where cirrus clouds can be embedded at some locations while there is clear air at others.
\end{abstract}

Correspondence to: P. Spichtinger

(peter.spichtinger@dlr.de)

\section{Introduction}

It is standard textbook knowledge that there are three ways by which air may become supersaturated (e.g. Young, 1993), viz. by diabatic cooling (e.g. via radiation), mixing (e.g. fog, condensation trails), and adiabatic cooling. When a supersaturated airmass is observed, we can ask which of the three ways has been taken to reach the supersaturated state. Certain signatures in the humidity and temperature fields can give hints to the answer. As an example we consider icesupersaturated regions (ISSRs). These exist in the middle to upper troposphere and even in the lowermost stratosphere over the mid-latitudes, the tropics and over Antarctica (Spichtinger et al., 2003b; Gierens et al., 2004). ISSRs are important for non-convective cirrus formation, for contrail persistence and for contrail-to-cirrus transformation. They are observed to be either colder or moister (or both) than their subsaturated environment (Gierens et al., 1999; Spichtinger et al., 2003b). These contrasts in temperature and moisture differ in magnitude (hence significance) from region to region and between troposphere to stratosphere. While a temperature contrast signifies cooling as the primary way to supersaturation, a moisture (i.e. absolute humidity) contrast points to convection or mixing.

So far, ISSRs have only been studied in a statistical sense; the humidity and temperature contrasts mentioned above are insights gained from statistical investigations. They, therefore, do not prove that, e.g. in a region where the average temperature contrast is large, ISSR formation is usually due to cooling of the respective airmass. Furthermore, the processes that lead to supersaturation can be superposed in a complex fashion, and there are more possibilities than one can distinguish by means of the two simple contrasts. In order to see better how ISSRs form, it is useful to conduct detailed case studies, using data from various sources. Later, after the principle processes are clearer, numerical simulations can be used to study a greater variety of cases.

(C) 2005 Author(s). This work is licensed under a Creative Commons License. 
As a prerequisite for a case study of ice supersaturation we need an in situ measurement of such an event. For this purpose we use the radiosonde soundings of the meteorological observatory at Lindenberg, Germany. Traditionally, humidity measurements in the upper troposphere are considered rather difficult and errors of the order of at least $10 \%$ generally must be accepted. However, the Lindenberg observatory has developed a technique to gauge and correct humidity measurements from routine $\mathrm{RS} 80 \mathrm{~A}$ radiosondes such that the results are claimed to be very precise even in the cold and dry tropopause region (Nagel et al., 2001). For the present investigation we do not require that humidity measurements be much more accurate than the mentioned $10 \%$ (since the maximum supersaturation measured exceeds $10 \%$ ), and we could already analyse ice supersaturation using the Lindenberg data in a previous paper (Spichtinger et al., 2003a). One disadvantage of using radiosonde data is that no cloud information is available; this means we are never sure whether the sonde was in clear air or in a cirrus cloud when it reported ice supersaturation. Hence, it makes sense to use the term ISSR for ice supersaturated air masses together with their embedded ice clouds.

We present a case study of the formation and evolution of an ice-supersaturated region measured by a radiosonde over the meteorological observatory at Lindenberg, Germany, on 29 November 2000, 06:00 UTC. We have selected this case because of the interesting and clear meteorological situation. The principle goal of this study is to investigate the life cycle of an ice-supersaturated region and how its evolution is affected by the large-scale synoptic development.

The paper is organized as follows: In Sect. 2 we describe the data sets used and our methods. Section 3 gives an overview of the synoptic situation. The case study is performed in Sect. 4 and in Sect. 5 we present a new method for visualising ice supersaturation on isobaric surfaces. Finally, we draw conclusions in Sect. 6. In two appendices we include the derivation of some equations relevant to this study.

\section{Data handling-description of methods}

The time of the ISSR observation from the Lindenberg radiosonde at 06:00 UTC 29 November 2000 will be referred to as $t=0 \mathrm{~h}$ in the following. For the present investigation we use several data sets:

\subsection{Radiosoundings}

First we use the vertical profiles (pressure, temperature and relative humidity, $R H$, vs. altitude) from the RS80A radiosoundings, corrected by the Lindenberg research team (Spichtinger et al., 2003a). The vertical resolution of this data is about $50 \mathrm{~m}$ (i.e. temporal resolution of $10 \mathrm{~s}$ ) and for (almost) each of the synoptic hours 00:00, 06:00, 12:00 and
18:00 UTC a complete vertical profile is available. The relative humidity with respect to ice $(\mathrm{RH} i)$ is calculated using

$R H i=R H \cdot \frac{e_{\mathrm{sw}}(T)}{e_{\mathrm{si}}(T)}$,

where $e_{\mathrm{sw}}$ and $e_{\mathrm{si}}$ denote the saturation water vapour pressure over water or ice, respectively. Additionally, the horizontal wind (components $u$ and $v$ ) is available in a vertical resolution of about $150 \mathrm{~m}$ (i.e. temporal resolution of $30 \mathrm{~s}$ ). Using the wind data we calculate the exact position of the radiosonde for a given time. Since the sonde does not furnish cloud information it is not possible from the sonde data alone to decide whether a humidity value in excess of ice saturation was measured inside a cloud or in clear air. For this we use satellite data.

\subsection{METEOSAT infrared data}

We use METEOSAT data to distinguish between measurements in clear and cloudy air. For this purpose a warped rectangle "GermanyNE" is clipped from the whole METEOSAT disc; the edges are (counted clockwise): $\quad\left(11.08^{\circ} \mathrm{E} / 54.99^{\circ} \mathrm{N}\right), \quad\left(16.21^{\circ} \mathrm{E} / 55.20^{\circ} \mathrm{N}\right)$, $\left(14.03^{\circ} \mathrm{E} / 49.58^{\circ} \mathrm{N}\right)$ and $\left(9.64^{\circ} \mathrm{E} / 49.43^{\circ} \mathrm{N}\right)$. We only use the infrared data, i.e. the calibrated brightness temperatures for wavelengths in the range $10.5 \leq \lambda \leq 12.5 \mu \mathrm{m}$. The horizontal resolution of this data is about $0.07^{\circ}$ in longitude and $0.15^{\circ}$ in latitude which corresponds to $5 \times 8 \mathrm{~km}^{2}$ in the midlatitudes (approximately $50^{\circ} \mathrm{N}$ ). The temporal resolution of the data is $30 \mathrm{~min}$.

\subsection{Meteorological analyses and trajectory calculations}

Another database for our study is the operational analyses of the European Centre for Medium-Range Weather Forecasts (ECMWF) global assimilation scheme at a resolution of T319L60 see e.g. Jakob et al. (2000); they constitute a consistent data set with a time resolution of $6 \mathrm{~h}$ (00:00, 06:00, 12:00 and 18:00 UTC). For our study, the required fields (temperature $T$, specific humidity $q$ and the wind components $u, v, \omega)$ are interpolated onto a regular latitudelongitude grid with a grid spacing of $0.6^{\circ}$. In the midlatitudes this corresponds approximately to $65 \mathrm{~km}$ in longitude and $45 \mathrm{~km}$ in latitude. Additionally, the surface pressure is available with the same horizontal resolution.

The operational wind analyses of ECMWF are the basis for the LAGRangian ANalysis TOol (LAGRANTO, see Wernli and Davies, 1997), a three-dimensional trajectory model. The timestep is $30 \mathrm{~min}$ and at every time the fields $T$ and $q$ are interpolated onto the actual position of the trajectories (longitude, latitude and pressure $p$ ). The relative humidity with respect to ice is calculated from the variables $T, q$ and $p$ using

$$
R H i=100 \% \cdot \frac{p \cdot q}{\epsilon \cdot e_{s i}(T)},
$$



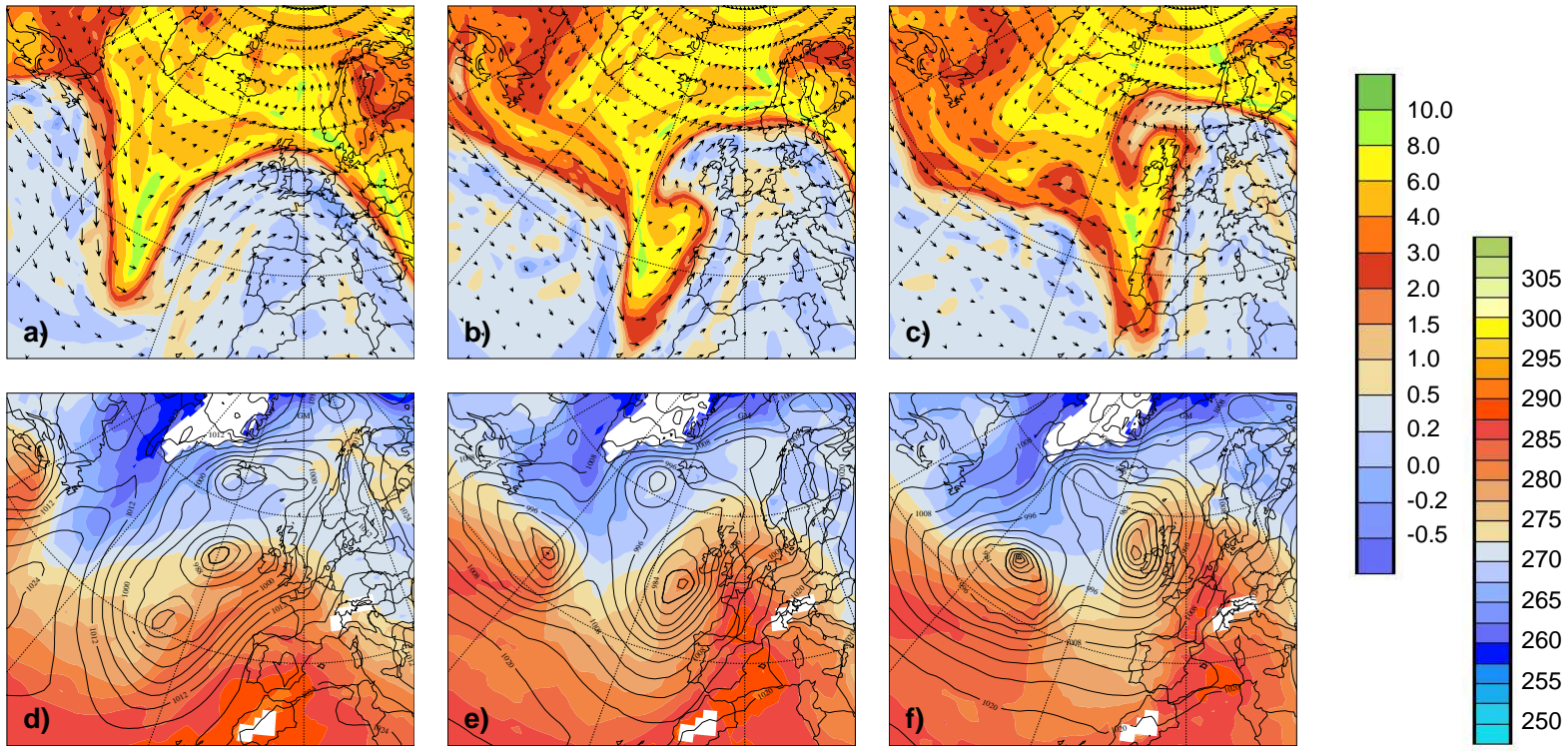

Fig. 1. Synoptic evolution from ECMWF analyses at times 18:00 UTC 27 November (left), 18:00 UTC 28 November (middle) and 06:00 UTC 29 November 2000 (right). Top panels show potential vorticity (in PVU, colours, left-hand colour table) and wind vectors on a $320 \mathrm{~K}$ isentropic surface, bottom panels surface temperature (in $\mathrm{K}$, colours, right-hand colour table) and sea level pressure (black contours with an interval of $4 \mathrm{hPa}$.)

where $\epsilon=M_{v} / M_{d} \approx 0.622$ denotes the quotient of the molar masses of water vapour and dry air. Hence, the change of $R H i$ can be studied along the trajectories.

\section{Synoptic overview}

A series of intense cyclones developed in the eastern North Atlantic during the last days of November 2000. The life cycle of one of these low pressure systems was essential for the formation of the ISSR that was observed over Northern Germany on 29 November 2000 and is therefore presented briefly in this section. At 18:00 UTC 27 November an intense ridge (characterized by air with low potential vorticity (PV) values on the 320-K isentrope, cf. Fig. 1a) was situated over western Europe. In the central Atlantic a rather narrow trough with peak PV-values larger than $8 \mathrm{PV}$ units (PVU) reached the Azores. It was accompanied by a surface cold front along which two cyclones formed (Fig. 1d). Ahead of the front, a pronounced and wide open warm sector extended to the British Isles. During the next $24 \mathrm{~h}$, the two cyclones merged and the surface frontal structure resembled a "T-bone" (Shapiro and Keyser, 1990) with the warm front stretching from west of Ireland to Poland and the cold front from the Bretagne to the Canary Islands (Fig. 1e). At upper levels the trough deformed and the high-PV stratospheric air has reached southwestern Europe (Fig. 1b). It induced an intense southwesterly warm flow from the subtropical Northern Atlantic to the UK. The northern border of the upperlevel ridge coincided with the position of the surface warm front (Fig. 1b, e). Also, just above the merged surface cyclones (slightly west of Ireland) the high- and low-PV air masses started to wrap up cyclonically, a typical indication for further cyclone intensification (e.g. Young et al., 1987). Indeed, $12 \mathrm{~h}$ later at 06:00 UTC 29 November the Low near Ireland has deepened by another $10 \mathrm{hPa}$ (Fig. 1f), the wrapup of stratospheric and tropospheric air masses on $320 \mathrm{~K}$ has continued (Fig. 1c) and the cold front has reached western Europe. It can also be noted that another cyclone formed rapidly in a region of strong baroclinicity and upper level winds in the central North Atlantic (Fig. 1f).

The development of the intense cyclone near Ireland with its pronounced warm sector that extended over Central Europe, prompted the investigation of warm conveyor belt-like flows in the eastern North Atlantic. Applying the technique introduced by Wernli and Davies (1997), a series of moist ascending airflows is identified. To this end, 48-h trajectories are calculated over the entire North Atlantic for a succession of time periods starting every $6 \mathrm{~h}$ and trajectories with an ascent of at least $600 \mathrm{hPa}$ are selected (see Wernli, 1997, for a detailed description of the approach). Figure 2 shows three time periods, each with a rather coherent, SW to NE oriented conveyor belt that is associated with the cyclone near Ireland and extended from the Atlantic Ocean south of $40^{\circ} \mathrm{N}$ to central and northern Europe $\left(50-70^{\circ} \mathrm{N}\right)$. Less typical, almost west-to-east oriented and less coherent moist ascending airstreams also occur in the central Atlantic in association with the rapid cyclogenesis in that area. These airflows all have the common physical characteristics of warm conveyor belts (Wernli, 1997; Eckhardt et al., 2004), namely an 

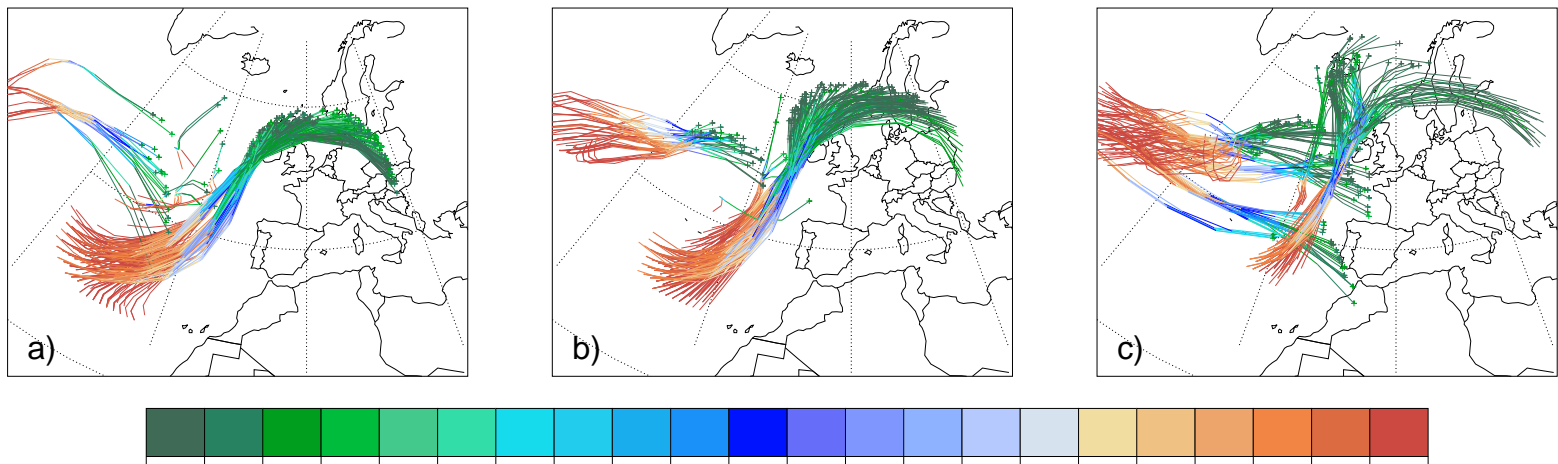

300325350375400425450475500525550580610640670700740780820860900940980

Fig. 2. Moist ascending airstreams with an ascent of more than $600 \mathrm{hPa}$ during the 48-h period starting at (a) 18:00 UTC $26 \mathrm{November,} \mathrm{(b)}$ 06:00 UTC 27 November and (c) 18:00 UTC 27 November 2000. Colours indicate pressure (in hPa).

ascent from the boundary layer $(\sim 970 \mathrm{hPa})$ to the upper troposphere $(\sim 330 \mathrm{hPa})$, a strong increase of potential temperature due to latent heat release (from about 293 to $315 \mathrm{~K}$ ) and a concomitant decrease of specific humidity (from about 10 to $0.1 \mathrm{~g} \mathrm{~kg}^{-1}$ ). The outflow of these conveyor belts reached parts of the UK, the North Sea, Scandinavia and Central Europe during the time period from 28-29 November 2000. As will be shown this was directly related with the formation of the ISSR.

\section{Case study of 29 November 2000}

In this section we present the analysis of the data sets mentioned above.

\subsection{Radiosonde profiles and ECMWF analyses}

In Fig. 3 the vertical profiles of temperature (Fig. 3a), specific humidity (Fig. 3b) and relative humidity with respect to ice (Fig. 3c) as obtained from the radiosounding (blue curves) are presented. Additionally, profiles obtained from ECMWF data (green filled circles and curves, see below), the thermal tropopause (horizontal pink line) and an ice supersaturation layer (red curve, see below) are shown. The specific humidity (radiosounding) is not measured directly by the radiosonde but it is calculated from the variables $T$, $p$ and $R H i$ using a modification of Eq. (2). In the following, we only describe the vertical profiles of temperature and relative humidity with respect to ice.

The temperature profile shows a decrease with height in the troposphere, with some exceptions: Around $p \approx 750 \mathrm{hPa}$ there is a strong temperature inversion, around $p \approx 350 \mathrm{hPa}$ there is a weaker one and at $p=172 \mathrm{hPa}$ we clearly identify the thermal tropopause. The $R H i$ profile is more complicated: In the pressure range $1000 \geq p \geq 760 \mathrm{hPa} R H i$ is quite high, at about $p \approx 760 \mathrm{hPa}$ the maximum is reached and then $R H i$ decreases rapidly with decreasing pressure. In the pres- sure range $550 \geq p \geq 350 \mathrm{hPa} R H i$ reaches high values (usually higher than $80 \%$ ) and partly exceeds saturation (maximum at $123 \%$ ). From about $p \approx 360 \mathrm{hPa}$ upwards the relative humidity decreases strongly with decreasing pressure. In the pressure range $280 \geq p \geq 170 \mathrm{hPa} R H i$ again reaches high values (partly in the range of supersaturation, maximum at $114 \%$ ). Above the tropopause the value of $\mathrm{RHi}$ decreases rapidly again.

We interpret both profiles ( $T$ and $R H i$ ) together: The two temperature inversions $(p \approx 760 \mathrm{hPa}, p \approx 360 \mathrm{hPa})$ are due to clouds with tops at $p \approx 760 \mathrm{hPa}$ and $p \approx 360 \mathrm{hPa}$, respectively. The lowest ice supersaturation layer (top pressure $p \approx 760 \mathrm{hPa}$ ) is probably a boundary layer water cloud. We are only interested in ice supersaturation so this cloud is not investigated further. In the following we concentrate on the pressure range $150-500 \mathrm{hPa}$. Also, the ice supersaturation layer with top pressure at $p \approx 360 \mathrm{hPa}$ can be interpreted as an opaque cloud due to the temperature inversion. This interpretation of the temperature inversion and the high humidities can be corroborated by the examination of the METEOSAT data in Sect. 4.2.

Next, we compare the radiosonde profile with the corresponding values from the ECMWF data set, retrieved from the nearest grid point to the actual position of the radiosonde (calculated via the wind profile of the radiosonde). The temperature profiles of radiosonde data and ECMWF data agree very well at most levels. Only in the pressure range $800 \geq p \geq 700 \mathrm{hPa}$ the agreement is moderate. The temperature inversion is not represented correctly by ECMWF presumably due to insufficient vertical resolution. But in the pressure range $150-600 \mathrm{hPa}$ the temperature profiles agree very well.

Since the ECMWF model does not represent supersaturation, its humidity variables must be treated with caution. As Ovarlez and van Velthoven (1997) have pointed out, the specific humidity obtained from ECMWF is usually lower than the specific humidity obtained from in situ measurements. 
However, although the absolute values are too low, the qualitative structure of the specific humidity data is quite good (see e.g. Ovarlez et al., 2000). This statement can be repeated and confirmed for the comparison of the two profiles (radiosonde, ECMWF) in this study: The quantitative agreement in specific humidity is not as good as for the temperature. In particular the values differ in the range around the two temperature inversions. But the qualitative structure of the radiosonde profile is captured quite well by the ECMWF data.

Finally we compare the profiles of $R H i$. Due to the low bias of the specific humidity in the ECMWF data set $\mathrm{RHi}$ is usually underestimated. But in the pressure range 150$500 \mathrm{hPa}$ the agreement in the structure is surprisingly good. In the upper three model levels the ECMWF analysis almost reaches saturation. Also the structure of the second supersaturation in the pressure range $350-500 \mathrm{hPa}$ is represented well. In contrast, the boundary layer cloud (near $p \approx 760 \mathrm{hPa}$ ) is not represented in the ECMWF data set.

From this comparison we see, that the structure of the $\mathrm{RHi}$ profile is represented well in the ECMWF data, in particular within the pressure range which we are interested in (150$500 \mathrm{hPa}$ ).

\subsection{Check for cloud presence}

By comparing the vertical profiles (temperature and relative humidity) of the radiosonde with the brightness temperatures obtained from METEOSAT we can decide whether the temperature inversion at $p \approx 360 \mathrm{hPa}$ is due to an opaque cloud and whether the supersaturation layer in the range $170 \leq p \leq 240 \mathrm{hPa}$ is cloud free or not (cf. Fig. 4). For this purpose we need the exact recording time of the METEOSAT picture and the positions of the air parcels measured by the radiosonde at this time. The scan of the whole earth disc by METEOSAT takes about $25 \mathrm{~min}$, hence we can estimate the time of the METEOSAT picture as 05:23 UTC. We need to know then where the air parcels that were at 05:23 UTC were measured by the radiosonde between about 05:20 UTC and 05:35 UTC. Using the radiosonde wind profile we determine these positions on the ECMWF model levels 29-36 (i.e. in the pressure range $\sim 200-390 \mathrm{hPa}$ ). They are close together and therefore we can fix a common mean position $\left(14.46^{\circ}\right.$ E $/ 52.14^{\circ} \mathrm{N}$, marked in Fig. 4, see below, by a filled triangle).

Figure 4 shows that the radiosonde (or the measured air parcels) is located in a region where the brightness temperature is about $-40 \lesssim T_{\text {sat }} \lesssim-30^{\circ} \mathrm{C}$, and is between two much colder regions $\left(T_{\text {sat }} \lesssim-45^{\circ} \mathrm{C}\right)$. For a more quantitative analysis we calculate the brightness temperature at the METEOSAT pixel nearest to the mean position. This is $T_{\text {nearest }}=-36.15^{\circ} \mathrm{C}$. Hence, we propose the following interpretation: In the radiosonde profiles ( $T$ and $\mathrm{RHi}$ ) there is a temperature inversion at $T \approx-36^{\circ} \mathrm{C}$ in conjunction with high relative humidities (up to saturation). In combination with
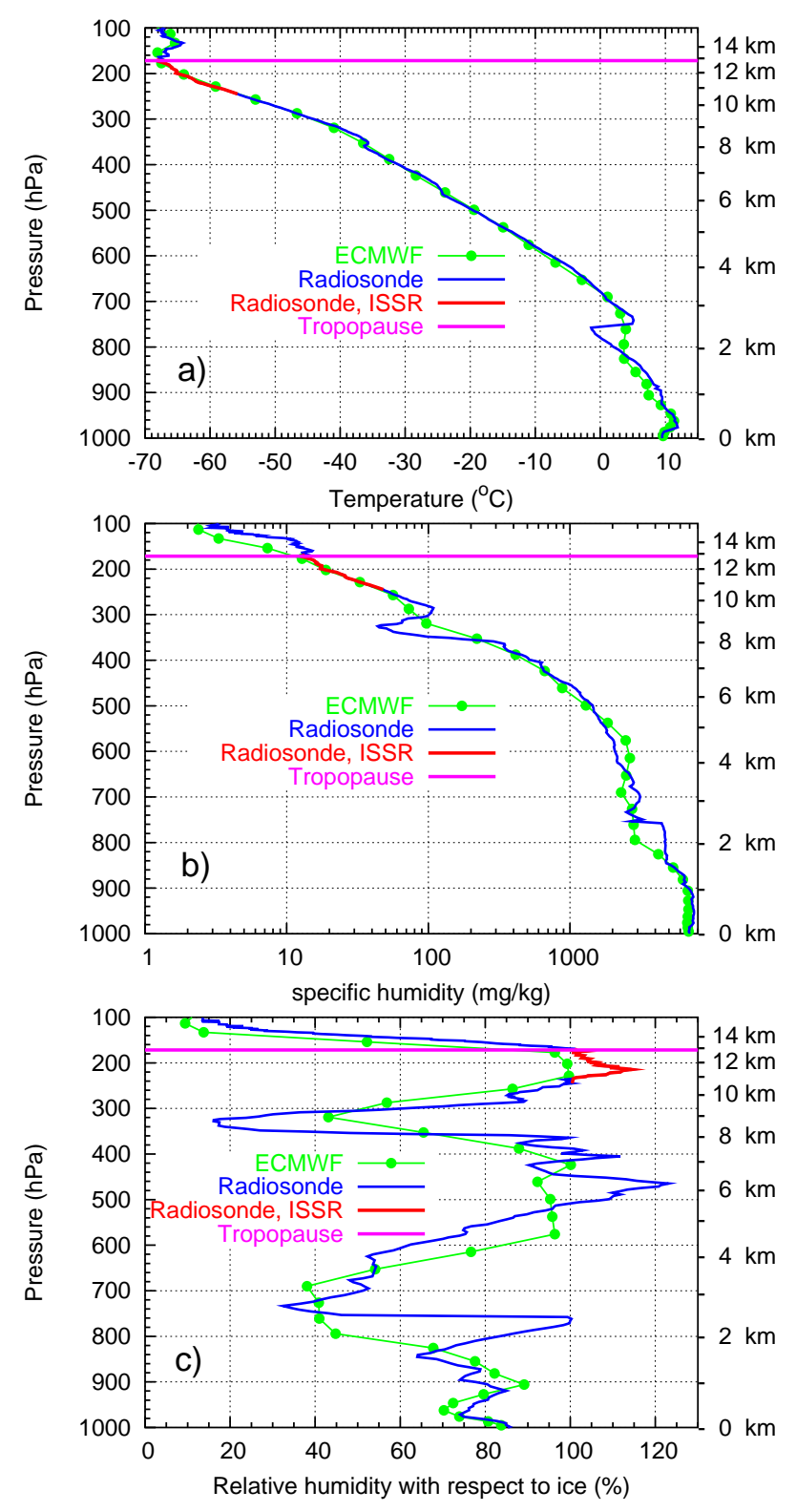

Fig. 3. Vertical profiles of the radiosonde (blue curve) and the corresponding values from the ECMWF data set (green filled circles and curve, values picked from the nearest grid points at every model level) on 29 November 2000, 06:00 UTC. Additionally, the thermal tropopause (horizontal pink line) and the reported ice supersaturated layer (red curve) obtained from the radiosonde are shown. (a) Temperature in degree Celsius; (b) Specific humidity in milligrams water vapour per kilogram dry air; (c) Relative humidity with respect to ice in percent.

the METEOSAT data we can conclude that this marks the top of an opaque cloud. Additionally, the high standard deviation $(\approx 6 \mathrm{~K})$ of the brightness temperature (evaluated over a $30 \times 30 \mathrm{~km}^{2}$ square) indicates a cloud layer. 


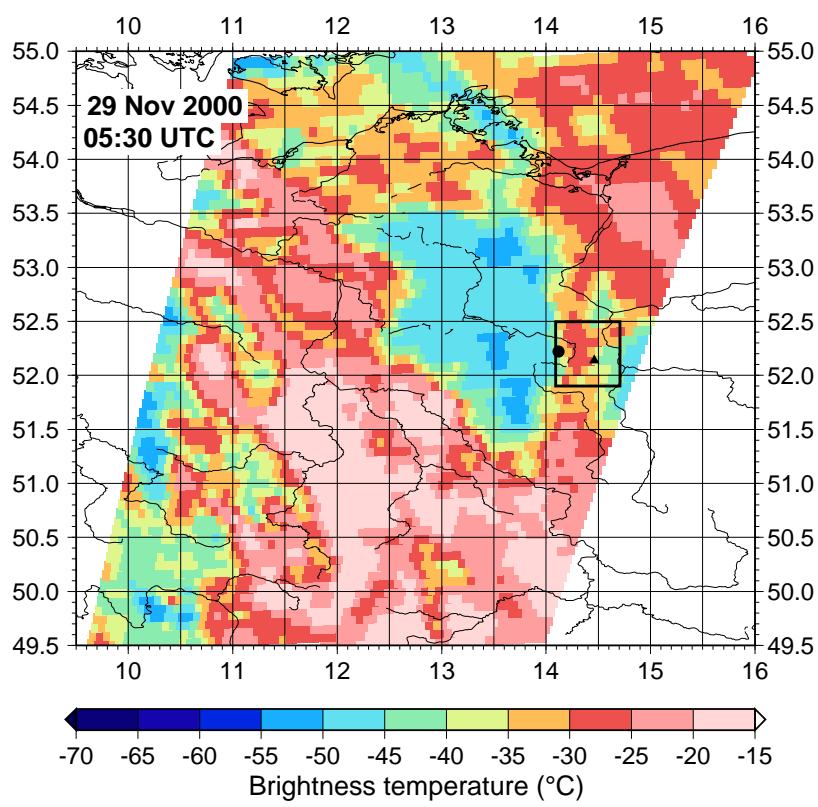

Fig. 4. Infra-red METEOSAT picture of the region "GermanyNE" $\left(9.5-16^{\circ} \mathrm{E}, 49.5-55^{\circ} \mathrm{N}\right)$ at 05:30 UTC (official time). Additionally, the positions of Lindenberg (filled circle) and of the air parcels measured by the radiosonde (filled triangle) are shown. Also, the nearest ECMWF grid point (open square, center at $14.4^{\circ} \mathrm{E} / 52.2^{\circ} \mathrm{N}$, extension $0.6^{\circ} \times 0.6^{\circ}$ ) is shown.

We can safely exclude a thick (or opaque) cirrus cloud in the pressure range $170 \leq p \leq 240 \mathrm{hPa}$, the upper ice supersaturation layer. If there was a thick cloud METEOSAT would measure brightness temperatures in the range $-70 \lesssim T_{\text {sat }} \lesssim-55^{\circ} \mathrm{C}$, since in the referred pressure range the radiosonde reports temperatures in the range $-68 \leq T \leq-58^{\circ} \mathrm{C}$. Yet a thin or subvisible cirrus cannot be excluded a priori. For determining the potential cloud properties of the supersaturation layer we first calculate the infrared optical depth $\tau$ using a simple radiative transfer calculation (for a derivation of the equation see Appendix A):

$\tau=\log \left(\frac{B_{\lambda}\left(T_{\text {surf }}\right)-B_{\lambda}\left(T_{\text {cloud }}\right)}{B_{\lambda}\left(T_{\text {sat }}\right)-B_{\lambda}\left(T_{\text {cloud }}\right)}\right) \mu$,

where $B_{\lambda}(T)$ denotes the Planck function at wavelength $\lambda$, $\mu=\cos \left(\varphi \approx 52^{\circ}\right)$.

Because of the inferred opaque cloud below at $p \approx 360 \mathrm{hPa}$ we can use its (mean) cloud top temperature as surface temperature in the equation above. The mean temperature in the top $500 \mathrm{~m}$ of the cloud is $T \approx-35^{\circ} \mathrm{C}$, the mean temperature of the supersaturation layer is $T \approx-64^{\circ} \mathrm{C}$, hence we set $T_{\text {surf }}=-35^{\circ} \mathrm{C}, T_{\text {cloud }}=-64^{\circ} \mathrm{C}$ and $T_{\text {sat }}$ varies between -37 and $-36^{\circ} \mathrm{C}$. The resulting optical depth varies within the range $0.014 \leq \tau \leq 0.054$, a typical value is $\tau \approx 0.026$. However, considering the accuracy of the brightness temperatures, the assumption of no cloud at all (i.e. $\tau=0$ ) is not in contradiction with our data.
Additionally, the ice water content (IWC) of this hypothetical cirrus cloud can be derived from the optical depth by the following equation (Appendix A):

$\mathrm{IWC}=\frac{\tau}{\beta \cdot \Delta z \cdot\left(\alpha_{i}+\frac{\gamma_{i}}{r_{\mathrm{eff}}}\right)}$.

The thickness of the supersaturation layer $(\Delta z)$ is about $2000 \mathrm{~m}$, for the wavelength range $8 \leq \lambda \leq 12.5 \mu \mathrm{m}$ we take from (Ebert and Curry, 1992) the constants $\alpha_{i}=0.0016 \mathrm{~m}^{2} \mathrm{~g}^{-1}$ and $\gamma_{i}=1.166 \mathrm{~m}^{2} \mathrm{~g}^{-1} \mu \mathrm{m}^{-1}$ and $\beta=1.66$ is the diffusivity factor. As the layer is very cold we can assume very small ice crystals with effective radius $r_{\text {eff }}=10 \mu \mathrm{m}$. If we insert the calculated values of the optical depth $\tau$, the resulting IWC varies within the range $0.068 \leq \mathrm{IWC} \leq 0.138 \mathrm{mg} \mathrm{m}^{-3}$. This is at the lower extreme of published values for IWC (Dowling and Radke, 1990).

Additionally, we calculate the IWC of the hypothetical cirrus at $T \approx-64^{\circ} \mathrm{C}$ using a formulation derived by Schumann (2002) from a multitude of in situ data:

$\operatorname{IWC}(T)=\exp \left(6.97+0.103 \cdot \frac{T}{{ }^{\circ} \mathrm{C}}\right) \frac{\mathrm{mg}}{\mathrm{m}^{3}}$

The resulting $\operatorname{IWC}\left(\operatorname{IWC}\left(-64^{\circ} \mathrm{C}\right)=1.459 \mathrm{mg} \mathrm{m}^{-3}\right)$ is about ten times higher than the IWC calculated from the optical depth $\tau$. Hence, if the considered ice supersaturation layer contained a cirrus it would have been an unusually tenuous object. From the radiosonde profile we calculate the mean water vapour content of the supersaturation layer $\bar{q}_{\text {tot }}=\frac{1}{\Delta z} \int q(z) \rho(z) d z \approx 7.2 \mathrm{mg} \mathrm{m}^{-3}$. Hence, the fraction of ice inside the layer would have been about $1-2 \%$ of the total water. But the maximum measured supersaturation inside this layer exceeds $10 \%$. If ice crystals had actually formed (by heterogeneous nucleation) the ice supersaturation layer would hardly have been affected by them, either because the crystal growth had been in an initial phase or because the hypothetical cirrus had been only a transient phenomenon (terminated by fall out of the ice crystals) and the ice supersaturation layer had not yet reached equilibrium. In any case we can exclude ice formation by homogeneous nucleation; this would need a supersaturation of about $60 \%$ at the observed temperature. This is far from the radiosonde measurement even if we take into account that even the corrected RS80A probably underestimates the humidity. Furthermore, the growth of the ice crystals at the necessary high supersaturation would quickly lead to a thick cloud that would be signalled in the METEOSAT data by very low brightness temperatures. These are not observed, neither at 05:30 UTC nor later.

Combining these results we can conclude that at the position where the radiosonde registered ice supersaturation in the pressure range $170 \leq p \leq 240 \mathrm{hPa}$ there was either no cloud at all or at most a tenuous cirrus whose ice crystals are formed by hetereogeneous nucleation. However, this does not exclude the possibility that thicker cirrus was nearby, 
Table 1. Properties of the ice supersaturation layer measured in the radiosonde profile.

\begin{tabular}{lllll}
\hline Variable & Min & Max & Mean $\pm \sigma$ & thickness \pm error \\
\hline$T\left({ }^{\circ} \mathrm{C}\right)$ & -68.2 & -57.9 & $-64.1 \pm 2.9$ & N/A \\
$q\left(\frac{m g}{k g}\right)$ & 12.5 & 38.3 & $21.1 \pm 7.2$ & N/A \\
$R H i(\%)$ & 100.3 & 114.4 & $105.3 \pm 4.1$ & N/A \\
$p(\mathrm{hPa})$ & 169.1 & 234.4 & N/A & $65.4 \pm 1.3$ \\
$z(\mathrm{~m})$ & 10869 & 12868 & N/A & $2049 \pm 50$ \\
\hline
\end{tabular}

as indicated by the colder brightness temperatures on the METEOSAT image.

Properties of the ice supersaturation layer are listed in Table 1 .

\subsection{Trajectory calculations}

\subsubsection{Trajectories}

We calculate forward $(t= \pm 0 \mathrm{~h} \rightarrow t=+24 \mathrm{~h})$ and backward $(t= \pm 0 \mathrm{~h} \rightarrow t=-36 \mathrm{~h})$ trajectories starting from a region around Lindenberg $\left(14.12^{\circ} \mathrm{E} / 52.22^{\circ} \mathrm{N}\right)$ : longitude $13.2-$ $16.2^{\circ} \mathrm{E}$, latitude $51.0-53.4^{\circ} \mathrm{N}$, pressure $170-510 \mathrm{hPa}$ (i.e. model levels 29-40). According to the horizontal grid resolution there are $6 \times 5=30$ grid points on every model level within the starting region. The combined forward and backward trajectories cover $-36 \mathrm{~h} \leq t \leq+24 \mathrm{~h}$, i.e. two and a half days. At time $t=0 \mathrm{~h}$ we determine for each considered model level the nearest grid point to the radiosonde position using the sonde's drift calculated from the wind data. The trajectory that originates from this (main) grid point is called the "main trajectory" in the following, hence there are 12 main trajectories for the 12 considered model levels. Additionally, the trajectories originating from the four grid points closest to the "main grid point" are examined. The trajectories are labelled as follows: $\operatorname{Tr}_{\ell, \mathrm{i}}$, where $\ell$ denotes the ECMWF level of the trajectory at $t=0 \mathrm{~h}$. $i$ is 1 for the main trajectory and 2-5 for the neighbouring trajectories (counted counterclockwise, starting at the northern grid point).

In Fig. 5 the five trajectories starting at $t=0 \mathrm{~h}$ at model level 30 (i.e. $\sim 229 \mathrm{hPa}$ ) are shown. The pattern of motion for the other trajectories is quite similar. For all trajectories on the 12 model levels we see the same type of vertical motion: Along the western part of the upper-level ridge there is slow upward motion leading to a weak ascent of the trajectories on the day before arriving over Lindenberg. On the downstream (eastern) side of the ridge the air parcels descend slowly.

For our further examination only the six upper model levels $(\ell \in\{29, \ldots, 34\})$ and their associated trajectories $\left(\operatorname{Tr}_{\ell, 1}-\operatorname{Tr}_{\ell, 5}\right)$ are considered because only on these levels there is ice supersaturation in the radiosonde profile. Hence, only for these trajectories are the following calculations re-

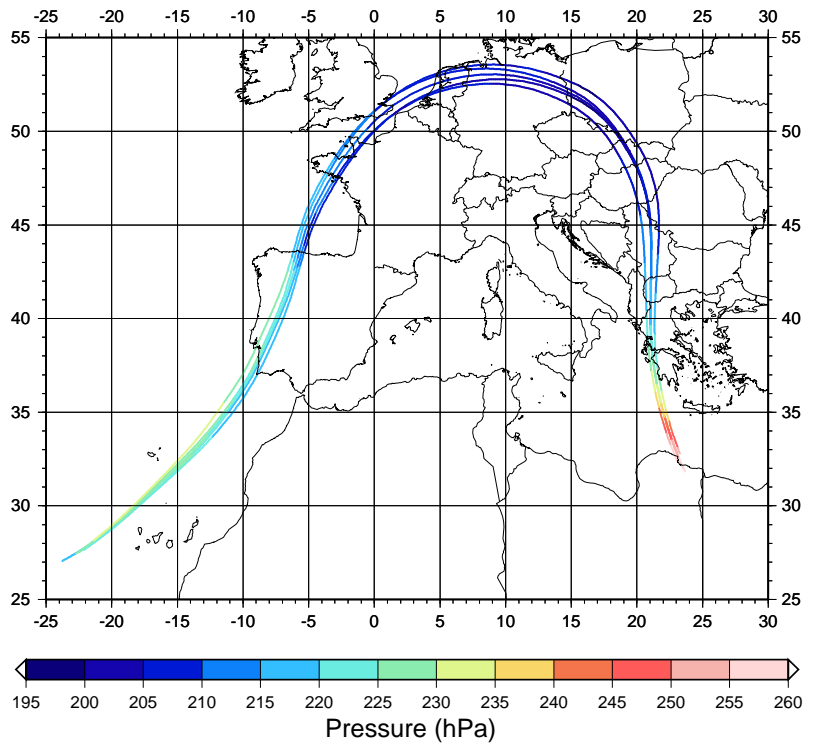

Fig. 5. Trajectories $\operatorname{Tr}_{30,1}-\operatorname{Tr}_{30,5}$ for the time period from 27 November 2000, 18:00 UTC to 30 November 2000, 06:00 UTC. The vertical coordinate is indicated by the colour bar.

ported. Usually, we examine all five trajectories on a pressure level (and corresponding minima, maxima and means of the several variables), but in most cases the evaluation of the variables along the main trajectory $\left(\operatorname{Tr}_{\ell, 1}\right)$ is sufficient. In particular, close to the starting point $(|\Delta t| \lesssim 18 \mathrm{~h})$ the differences between the five trajectories (regarding the variables) are minimal.

\subsubsection{Contributions to the change of relative humidity with respect to ice}

At the beginning of this paper we raised the question whether it is possible to determine how an observed supersaturated airmass has reached supersaturation. We try this by considering the tendencies of $\mathrm{RHi}$ along the trajectories. $\mathrm{RHi}$ can be calculated from the three variables $T, q$ and $p$ using Eq. (2). These variables are available along the trajectories. Hence, one may ask which variable $(T, q, p)$ has the dominant impact on the change of $R H i$, i.e., the variable causes the most change on $R H i$. The contributions of the three variables can be expressed by the total differential $d R H i$ :

$$
d R H i=\frac{\partial R H i}{\partial T} d T+\frac{\partial R H i}{\partial q} d q+\frac{\partial R H i}{\partial p} d p
$$

Expressions for the partial derivatives are given in Appendix $\mathrm{B}$. This linearisation is appropriate provided the atmosphere does not change too much between two time steps. This is generally the case here. For easier comparison of the contributions we normalise them through division by $\delta R H i$, the change of $\mathrm{RHi}$ from one time step to the next.

We concentrate on the upper three levels where the ice supersaturation appears. For the trajectories $\operatorname{Tr}_{29, \mathrm{i}}, \operatorname{Tr}_{30, \mathrm{i}}$ and 

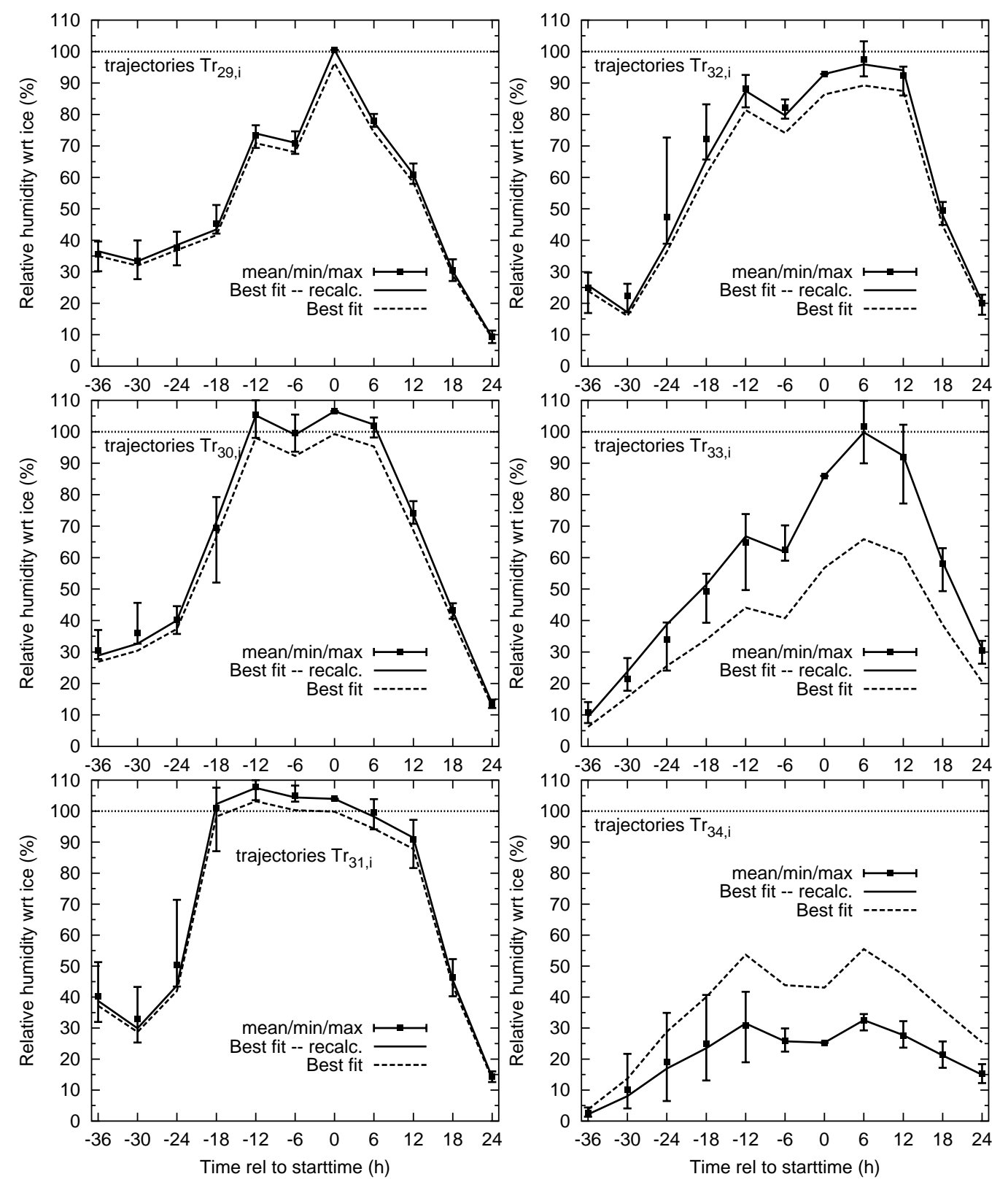

Fig. 6. $R H i$ along the mean trajectories as reported in the ECMWF data set (dashed curves) and recalculated using the tendencies of specific humidity (solid curves). Additionally, the minima, maxima and the mean values of the recalculated $R H i$ values along the five trajectories (error bar and filled square) are presented.

$\operatorname{Tr}_{31, \mathrm{i}}$ the change of $R H i$ is always dominated by the contributions from the temperature, i.e. the normalised contribution of the temperature change is almost always greater than $2 / 3$ and always greater than $1 / 2$. Hence, we can say that the formation and development of the ISSR is dominated by temperature.

The dominating impact of temperature on the evolution of $R H i$ together with the low optical thickness of the ISSR leads to the conclusion that in this case adiabatic cooling was the pathway to supersaturation.

\subsubsection{Recalculation of the relative humidity}

As Ovarlez et al. (2000) have pointed out, the qualitative structure of the specific humidity field in the ECMWF data set is quite well represented. But since the specific humidity is systematically underestimated, so is $R H i$. This makes it very difficult to decide whether an air parcel reaches saturation or not. To avoid this problem we propose the following working hypothesis: The gradients of the specific humidity field are portrayed in the correct relative proportion in the 
ECMWF data set, but the absolute values are wrong. The correct absolute values can be obtained from the radiosonde: (1) At $t= \pm 0 \mathrm{~h}$ the $R H i$ reference value is determined by $R H i_{\text {ref }}=R H i_{\text {radiosonde }}$. For consistency with the subsequent calculations we also set $T_{\text {ref }}=T_{\mathrm{ECMWF}}$ and $p_{\text {ref }}=p_{\mathrm{ECMWF}} . q_{\mathrm{ref}}$ is then given by Eq. (2). Hence, at $t= \pm 0 \mathrm{~h}$ we have reference values $\left(R H i_{\text {ref }}, T_{\text {ref }}, q_{\text {ref }}, p_{\text {ref }}\right)$ for each model level.

(2) For each timestep $t_{i} \rightarrow t_{i+1}$ (forward trajectory) or $t_{i} \rightarrow t_{i-1}$ (backward trajectory), we calculate the relative increase or decrease, $\left(q\left(t_{i+1}\right)-q\left(t_{i}\right)\right) / q\left(t_{i}\right)$ or $\left(q\left(t_{i}\right)-q\left(t_{i-1}\right)\right) / q\left(t_{i}\right)$, respectively. Here, the specific humidity $q$ along the trajectories (i.e. from ECMWF data) is used. Using these relative changes, the specific humidity can be recalculated. The calculation starts at $t= \pm 0 \mathrm{~h}$ (i.e. $q(t=0)=q_{\text {ref }}$ ) and proceeds successively forward and backwards in time.

(3) From the recalculated specific humidity a recalculated $\mathrm{RHi}$ is derived via Eq. (2), using the temperature and pressure values along the trajectory (i.e. ECMWF data).

With this recalculated $\mathrm{RH} i$ the evolution of the ISSR becomes clearer because now values above saturation are possible. One must, however, not interpret the recalculated $\mathrm{RH} i$ values as the truth; but they are probably more realistic than the original ECMWF data and our view of the formation and evolution of the ISSR gets more illustrative when we use the recalculated humidity fields. This calculation is done for all upper trajectories $\left(\operatorname{Tr}_{29, \mathrm{i}}-\operatorname{Tr}_{34, \mathrm{i}}\right)$; the results are shown in Fig. 6 and discussed next.

\subsubsection{Vertical extension and evolution of the ISSR}

Using the recalculated $R H i$, formation and duration of ice supersaturation in the air parcels considered in Sect. 4.3 can be estimated. For estimating the vertical extension of the ISSR one has to remember that the vertical resolution of the ECMWF data in the upper troposphere is $38 \geq \Delta p \geq 24 \mathrm{hPa}$ (pressure coordinates), and $540 \leq \Delta z \leq 860 \mathrm{~m}$ (height coordinates), and one has to check that the trajectories are approximately on top of each other. As this is the case here, we can consider the vertical distance between the trajectories. From these values we can estimate the thickness of the icesupersaturated regions with an error estimation of half of the maximum distance between the trajectories/layers.

The air parcel on trajectory $\operatorname{Tr}_{31,1}$ joins the ISSR at $t=-18 \mathrm{~h}$ relative to the radiosonde ascent, i.e. 28 November 2000, 12 UTC (see Fig 7). At that time the (recalculated) $R H i$ reaches supersaturation, and the actual pressure is about $p \approx 243 \mathrm{hPa}$. The vertical extension of the ISSR is about $\Delta z \approx 770 \pm 400 \mathrm{~m}$.

At $t=-12 \mathrm{~h} R H i$ on trajectory $\operatorname{Tr}_{30,1}$ also reaches supersaturation and $R H i$ on $\operatorname{Tr}_{31,1}$ increases. Hence, the ISSR expands and the vertical extension is about $\Delta z \approx 1550 \pm 450 \mathrm{~m}$.

At $t=-6 \mathrm{~h} R H i$ remains level or even decreases a bit on $\operatorname{Tr}_{30,1}$ and $\operatorname{Tr}_{31,1}$. Yet, both trajectories are still part of the ISSR. The vertical extension of the ISSR stays almost con-

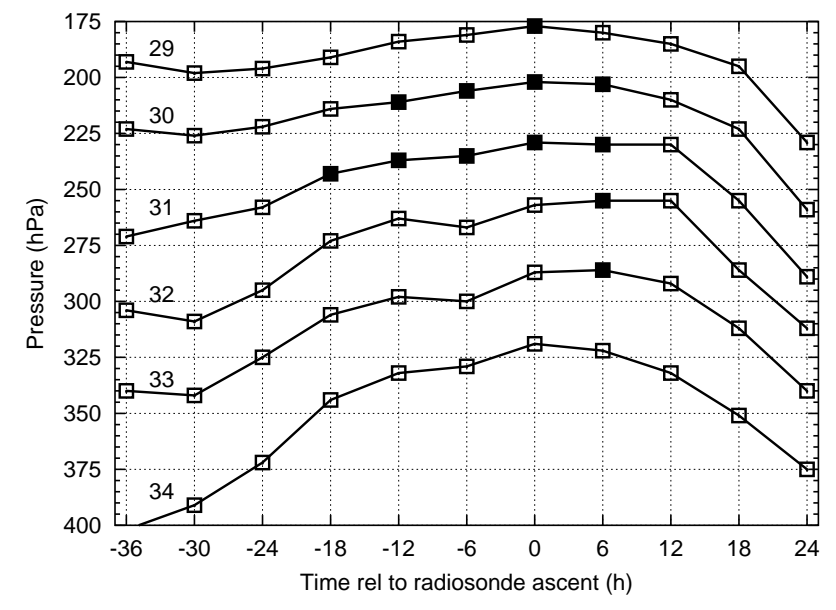

Fig. 7. Formation and evolution of the ISSR (filled square) along the main trajectories $\operatorname{Tr}_{29,1}-\operatorname{Tr}_{34,1}$ (lines with open squares). The time is shown relatively to the radiosonde ascent at 29 November 2000, 06:00 UTC.

Table 2. Formation and development of the measured ISSR. Additionally, its estimated vertical extension (pressure and absolute distance) are given. $\operatorname{Tr}_{\ell, \mathrm{i}}$ means trajectory $i$ on ECMWF model level $\ell$.

\begin{tabular}{rllr}
\hline Time & Position & $\Delta p(\mathrm{hPa})$ & $\Delta z(\mathrm{~m})$ \\
\hline$t=-18 \mathrm{~h}$ & $\operatorname{Tr}_{31,1}$ & $29 \pm 15$ & $770 \pm 400$ \\
$t=-12 \mathrm{~h}$ & $\operatorname{Tr}_{30,1} / \operatorname{Tr}_{31,1}$ & $52 \pm 13$ & $1550 \pm 450$ \\
$t=-6 \mathrm{~h}$ & $\operatorname{Tr}_{30,1} / \operatorname{Tr}_{31,1}$ & $57 \pm 16$ & $1650 \pm 400$ \\
$t= \pm 0 \mathrm{~h}$ & $\operatorname{Tr}_{29,1}-\operatorname{Tr}_{31,1}$ & $77 \pm 14$ & $2450 \pm 450$ \\
$t=+6 \mathrm{~h}$ & $\operatorname{Tr}_{30,1}-\operatorname{Tr}_{33,1}$ & $112 \pm 18$ & $3000 \pm 400$ \\
\hline
\end{tabular}

stant: $\Delta z \approx 1650 \pm 400 \mathrm{~m}$. At the time of the radiosonde ascent $(t= \pm 0 \mathrm{~h})$ supersaturation appears on level 29 (i.e. $\operatorname{Tr}_{29}$ joined the ISSR from levels 30 and 31, see Fig. 3). The thickness of the ISSR is estimated to be about $\Delta z \approx 2450 \pm 450 \mathrm{~m}$. Within the error there is a good agreement with the value measured by the radiosonde: $\Delta z_{\mathrm{RS}}=2049 \pm 50 \mathrm{~m}$.

At $t=+6 \mathrm{~h}$ the ascent of the considered trajectories becomes slower, therefore $R H i$ decreases slowly and the air parcels start to leave the ISSR: Along the trajectories $\operatorname{Tr}_{29, \mathrm{i}}$ the $\mathrm{RHi}$ falls below saturation, but along the trajectories $\operatorname{Tr}_{30, \mathrm{i}}$ and $\operatorname{Tr}_{31, \mathrm{i}} R H i$ still has values above saturation. Hence, these trajectories are still part of the ISSR. According to the recalculation $R H i$ reaches values near or even above saturation on most of the trajectories $\operatorname{Tr}_{32, \mathrm{i}}$ and $\operatorname{Tr}_{33, \mathrm{i}}$. Thus we can identify the ISSR on trajectories $\operatorname{Tr}_{30, \mathrm{i}}-\operatorname{Tr}_{33, \mathrm{i}}$. The vertical extension of the ISSR reaches $\Delta z \approx 3000 \pm 400 \mathrm{~m}$.

At $t=+12 \mathrm{~h}$ there is no supersaturation on the trajectories $\operatorname{Tr}_{29, \mathrm{i}}-\operatorname{Tr}_{34, \mathrm{i}}$ (except for trajectory $\operatorname{Tr}_{33,3}$ ). Hence, at this point the trajectories are no longer part of the ISSR, because $R H i$ falls below saturation according to the descent of the 
$\begin{array}{llllllllllllllllllllllllllllll}-30 & -25 & -20 & -15 & -10 & -5 & 0 & 5 & 10 & 15 & 20 & 25 & 30 & 35 & 40 & -30 & -25 & -20 & -15 & -10 & -5 & 0 & 5 & 10 & 15 & 20 & 25 & 30 & 35 & 40\end{array}$
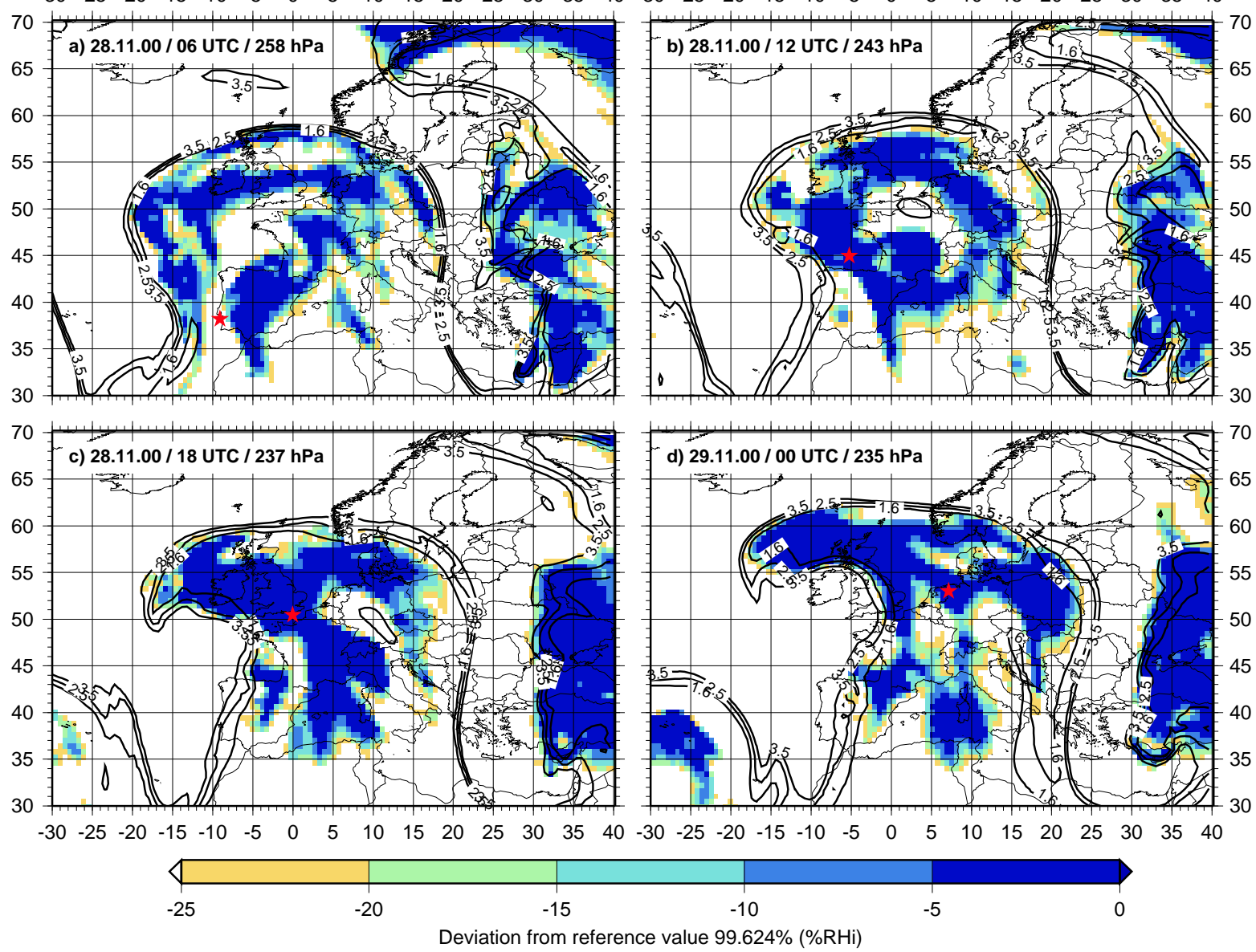

Fig. 8. Evolution of the ice supersaturation layer, measured by the radiosonde at 29 November 2000, 06:00 UTC along the trajectory Tr 31,1 $(-24 \mathrm{~h} \rightarrow-6 \mathrm{~h})$ : (a) $t=-24 \mathrm{~h}, p=258 \mathrm{hPa}$; (b) $t=-18 \mathrm{~h}, p=243 \mathrm{hPa}$; (c) $t=-12 \mathrm{~h}, p=237 \mathrm{hPa}$; d) $t=-6 \mathrm{~h}, p=235 \mathrm{hPa}$. The reference value of $R H i$ has been taken from the comparison of the radiosonde and ECMWF data at $t= \pm 0$ (radiosonde ascent). The position of the trajectory is marked by a red star. The solid black curves mark potential vorticities of 1.6, 2.5, and 3.5 PVU, respectively.

air parcels and the resulting temperature increase.

It may be noted that above and below the supersaturated layer there was always strong subsaturation, hence these supersaturated layers seem to be strictly confined vertically.

The evolution of the ISSR along the upper trajectories is visualised in Fig. 7. The black filled squares indicate ice supersaturation. Table 2 summarises the evolution of the ISSR.

The duration of the considered air parcels within the ISSR can be estimated in the following way: Ice supersaturation has been detected for the first time at $t=-18 \mathrm{~h}$ and the last definite measurement of supersaturation is at $t=+6 \mathrm{~h}$. The times for start and end of the supersaturation period are both uncertain within a $6 \mathrm{~h}$ window. Without additional information we assume a uniform probability distribution for these instances with mean $3 \mathrm{~h}$ and variance $3 h^{2}$. Hence, we estimate the error by $\Delta t=\sqrt{3+3} h \approx 2.5 \mathrm{~h}$ and can finally estimate the time the airparcels were part of the ISSR as $24+(6 \pm 2.5) \mathrm{h}$. It should be noted that a life time of the ISSR itself has not been determined; perhaps it is an inappropriate notion because it may be difficult to define ISSRs as single entities. Air parcels may join an ISSR and eventually leave it, but the ISSR is still there.

Using AVHRR (Advanced Very High Resolution Radiometer) infrared images at several times we can exclude the formation of a thick cirrus at the positions of the upper three trajectories. Hence, the supersaturation measured by the radiosonde formed by uplift with adiabatic cooling (cf. Sect. 4.3.2), stayed for a while and disappeared without forming a visible (or even opaque) cirrus cloud. Especially, homogeneous nucleation can be excluded as shown above (cf. Sect. 4.2). A few crystals could have nucleated hetereogeneously and formed a subvisible or thin cirrus that had probably not reached phase equilibrium. Cirrus clouds could nevertheless be around in the neighbourhood, but the air parcels followed by the trajectory calculations were probably clear. 


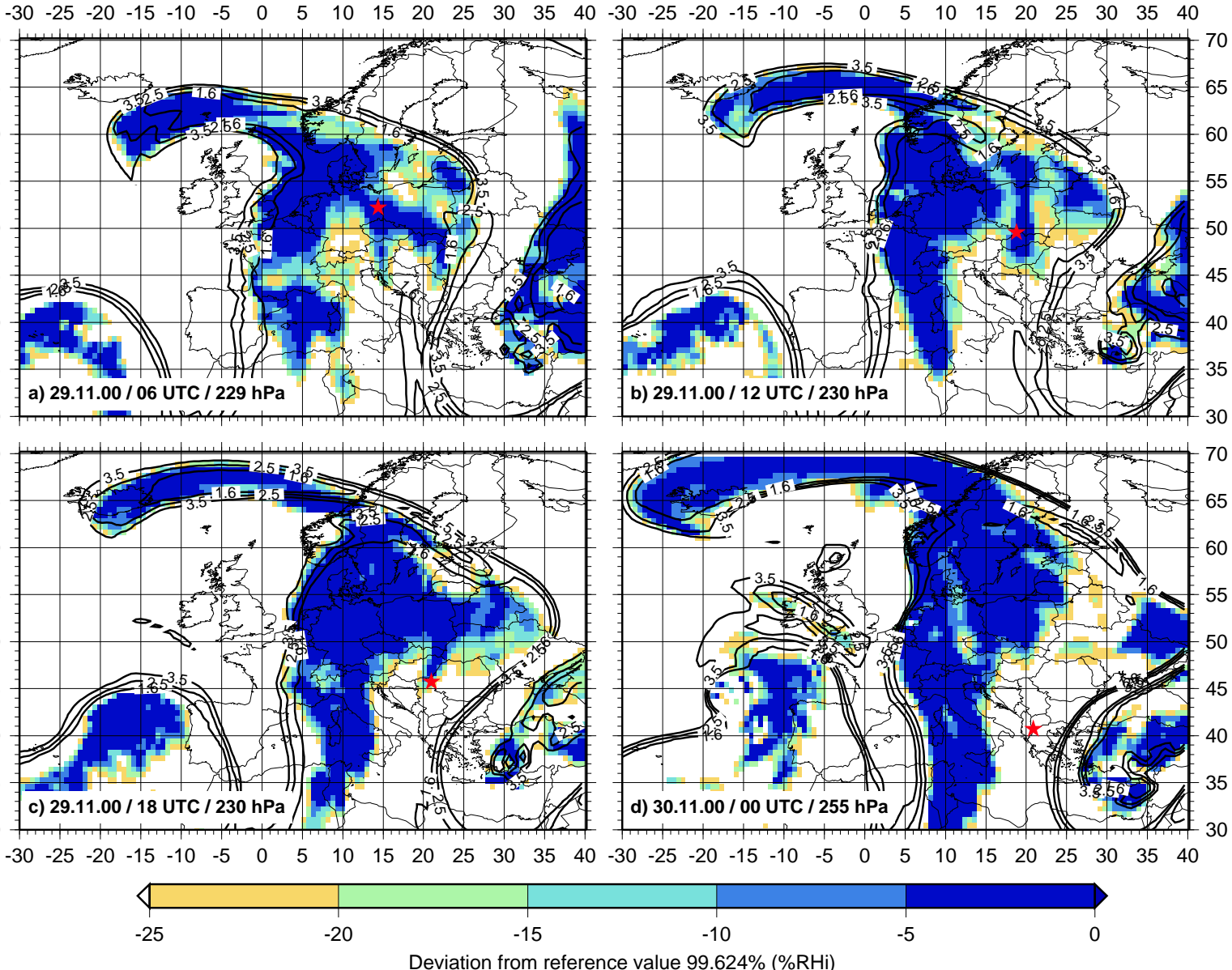

Fig. 9. Evolution of the ice supersaturation layer, measured by the radiosonde at 29 November 2000, 06:00 UTC along the trajectory Tr 31,1 $( \pm 0 \mathrm{~h} \rightarrow+18 \mathrm{~h}$ ): (a) $t= \pm 0 \mathrm{~h}, p=229 \mathrm{hPa}$; (b) $t=+6 \mathrm{~h}, p=230 \mathrm{hPa}$; (c) $t=+12 \mathrm{~h}, p=230 \mathrm{hPa}$; (d) $t=+18 \mathrm{~h}, p=255 \mathrm{hPa}$. The reference value of $R H i$ has been taken from the comparison of the radiosonde and ECMWF data at $t= \pm 0$ (radiosonde ascent). The position of the trajectory is marked by a red star. The solid black lines are as in Fig. 8.

\section{Ice supersaturation on isobaric surfaces}

So far our analysis has only shown the vertical depth of the ISSR but we have no information about its horizontal extension. Gierens and Spichtinger (2000) estimated horizontal extensions of ISSRs using the pathlengths that MOZAIC (Measurement of Ozone by Airbus In-Service Aircraft, Marenco et al., 1998) aircraft flew within ISSRs. But they already noted a severe selection bias inherent in their method (such that larger larger ISSRs have a greater chance to be passed by an aircraft than smaller ones). Furthermore they had to assume a circular shape of the ISSRs to obtain a size distribution.

In this study we visualise the horizontal extension of the observed ISSR on pressure surfaces using $\mathrm{RHi}$ from the ECMWF analyses. Unfortunately, the ECMWF model does not allow supersaturation as mentioned before, so we cannot simply look for grid points with $R H i \geq 100 \%$.
Hence, we use the following more qualitative approach. The radiosonde measures ice supersaturation on several pressure levels (or ECMWF model levels). The corresponding ECMWF $R H i$ value at the nearest grid point is usually below $100 \%$. We can then assume that the difference between the radiosonde humidity and the nearest ECMWF value is a lower bound of the actual negative bias of the humidity field in the model on the level in question. Since the radiosonde itself underestimates the true supersaturation (for example due to its response time resulting in moving averages over humidity maxima), the actual bias is still larger than this estimate. We now take the model value at the nearest grid point as a supersaturated reference value and mark all grid points where $R H i$ is less than the reference value by no more than $\triangle R H i$, a difference that can be at least as large as the bias determined before. Varying $\Delta R H i$, we can visualise the horizontal gradient of the humidity field and we see the sharpness of the boundaries of ISSRs. The temporal evolution of the ISSRs can be visualised when the same reference value 
and the same $\Delta R H i$ values are used throughout the period considered here.

Using this technique we can visualise the horizontal extension and development of an ISSR for the first time. In Figs. 8 and 9 we show the evolution of the ISSR on pressure levels that follow the trajectory $\operatorname{Tr}_{31,1}$. At $t=-24 \mathrm{~h}$ the position of the trajectory is definitely outside the supersaturated air (Fig. 8a). At $t=-18 \mathrm{~h}$ the trajectory is inside a region with high $\mathrm{RHi}$ (Fig. 8b). We have ice supersaturation by then, in agreement with our analysis from Fig. 7. Thereafter the trajectory stays in the ISSR for another $24 \mathrm{~h}$ (Figs. 8c, d, 9a, b). It leaves the supersaturated air at about $t=+12 \mathrm{~h}$ (Fig. 9c) and is completely outside of it $6 \mathrm{~h}$ later (Fig. 9d). For all pressure levels passed by the trajectory $\operatorname{Tr}_{31,1}$ the reference value is $99.6 \%$. Because of the strong horizontal humidity gradients we see that the structure of the ISSR is not very sensitive to the exact reference value.

Looking at Figs. 8 and 9 we get an impression of the complicated structure of ISSRs. We have additionally calculated the area and the perimeter of these regions for varying values of $\Delta R H i$. This shows a fractal structure for ISSRs: When we plot $\log ($ area $)$ vs. $\log$ (perimeter) the slope of the resulting line is less than 2 (not shown), which is typical for fractals.

Additionally, we can observe another effect: The ISSRs usually appear close to the tropopause (indicated by the three isolines of potential vorticity $P V=1.6,2.5,3.5 \mathrm{PVU}$ ) and reach into the stratosphere only rarely (see e.g. Spichtinger et al., 2003a). The supersaturated regions often follow the shape of the tropopause.

In order to see the relationship between the warm conveyor belt (cf. Sect. 3) and the ISSR another set of trajectory calculations is performed. At every horizontal position of an ISSR in Fig. 8 and Fig. 9 several backward trajectories are calculated at the level of the ISSR and below, on each model level from 150 to $600 \mathrm{hPa}$. Then, at every location the maximum vertical displacement from this stack of 48-h backward trajectories is determined and plotted in Fig. 10. There seems to be a clear separation between regions where the maximum vertical displacement is very large (larger than $500 \mathrm{hPa}$ ) and regions where it is considerably smaller (less than $300 \mathrm{hPa}$ ). Note that this is not necessarily the vertical displacement of the ISSR air parcels themselves, but the maximum value of all air parcels situated just below. According to Fig. 10, the ISSRs can be roughly divided into two categories. The first category (that also contains the region of the observed ISSR discussed in detail above) is characterised by relatively weak ascent of its air masses and of all the air masses below the ISSR. The second category (typically to the north of the first category) contains ISSRs that are located exactly above the outflow of the warm conveyor belt and experienced a very strong ascent in the previous 1-2 days. There are also physical differences between the two categories. The specific humidities are on the average smaller and the temperatures lower at the grid points that are located over the warm conveyor belt than at the grid points over the weak ascent region.
However, with regard to $\mathrm{RHi}$ these differences cancel, and we find on average no significant difference in $R H i$ values between the two ISSR categories.

\section{Conclusions}

In this case study we have analysed the formation and evolution of an ice supersaturated region, detected by a radiosonde over Lindenberg, Germany, on 29 November 2000, 06:00 UTC. This region was crossed by the sonde in the pressure range $169.1 \leq p \leq 234.4 \mathrm{hPa}$ near the thermal tropopause ( $p \approx 172 \mathrm{hPa}$ ). On the flight path of the radiosonde the ISSR was probably clear air, yet the presence of a very faint ice cloud cannot be excluded. At least, the derived IWC of about $0.1-0.2 \mathrm{mg} \mathrm{m}^{-3}$ is at the lower extreme of published values (Dowling and Radke, 1990, their Tables 3 and 4). At other locations the ISSR did probably contain cirrus clouds, as indicated by the METEOSAT image.

In order to study the life cycle of the ISSR we have performed trajectory calculations. For this we used the Lagrangian 3-D trajectory model LAGRANTO driven by wind field from ECMWF meteorological analyses. We have calculated the contributions of the variables $T, q, p$ to the change of relative humidity with respect to ice $(\mathrm{RHi})$ along the trajectories. In our case it turned out that the $R H i$ evolution was dominated by the changes of temperature. This fact and the low optical thickness of the ISSR demonstrate that adiabatic processes were responsible for its formation. One of the trajectories was in the supersaturated state for more than $24 \mathrm{~h}$. While the ISSR was less than $1 \mathrm{~km}$ thick at the point where that trajectory joined it, it was much thicker later on. At the time and location of its detection by the radiosonde it was more than $2 \mathrm{~km}$ thick, and thereafter we could determine a maximum depth of about $3 \mathrm{~km}$ before the trajectories left the ISSR. It can be stated that this was an unusually thick specimen of ISSRs; typically the average thickness of such regions over Lindenberg is about $500 \mathrm{~m}$ (Spichtinger et al., 2003a). We could also see that the supersaturated region was always embedded vertically within strongly subsaturated layers.

Finally, we have presented a qualitative visualisation of the appearence of ice supersaturated regions on isobaric surfaces (Figs. 8 and 9). This gave an impression of the complicated structure of these regions and of their true horizontal extension. The complicated structure of the ISSRs expresses itself in the fractal nature of the area-to-perimeter relation that can be derived from the maps. It was also shown how the dynamics of the weather systems impact upon the generation of these layers. A part of the identified ISSR was located just above the outflow of an intense warm conveyor belt associated with significant cyclone deepening over the eastern North Atlantic. In the rear of this event associated with strong upward motion, a second category of ISSR formed associated with weaker vertical motion within the ISSR and 


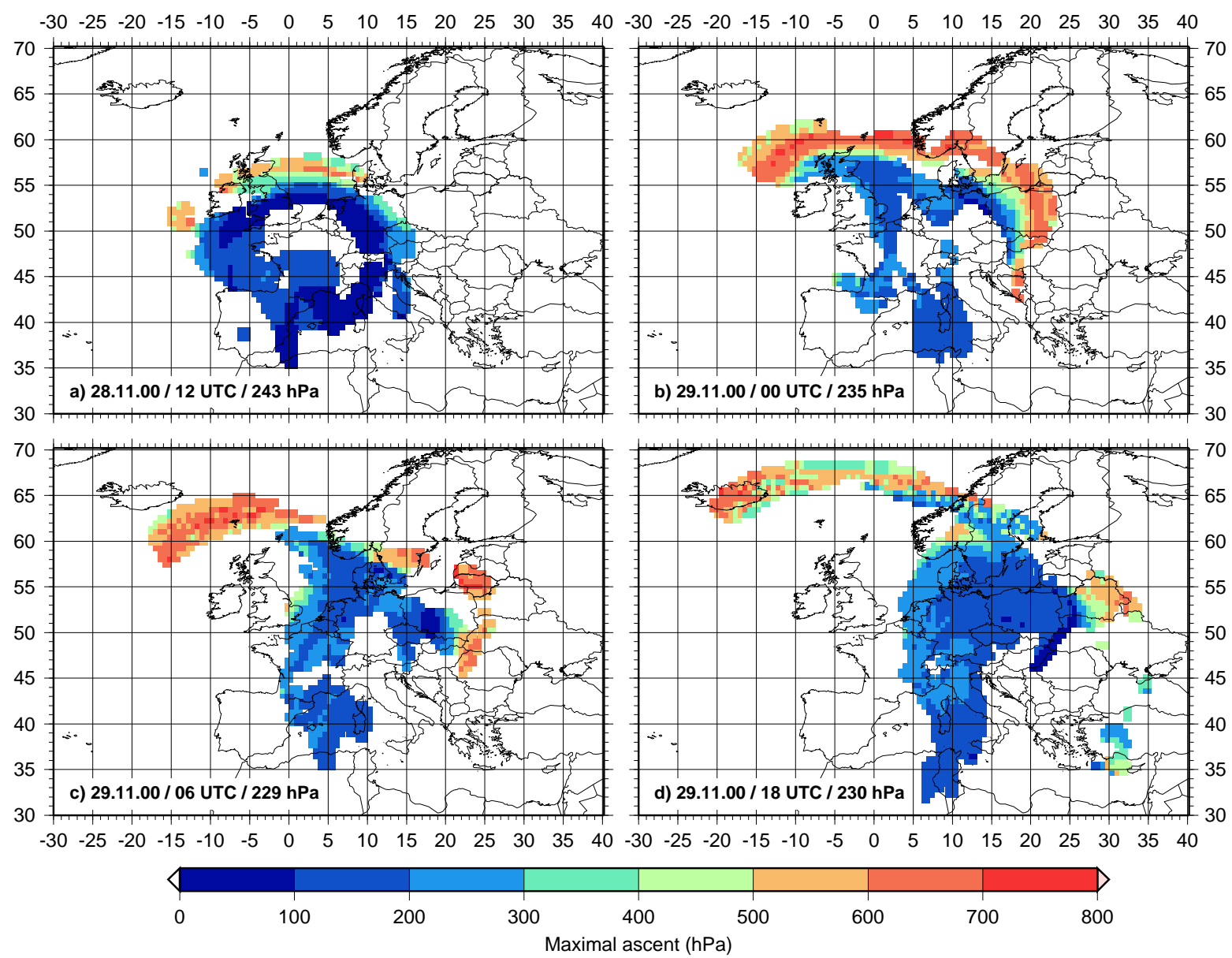

Fig. 10. The maximal ascent of $48 \mathrm{~h}$ trajectories ( $24 \mathrm{~h}$ in the upper left panel) are shown for some of the ISSR areas of Figs. 8 and 9 : (a) $t=-18 \mathrm{~h}, p=243 \mathrm{hPa}$; (b) $t=-6 \mathrm{~h}, p=235 \mathrm{hPa}$; (c) $t=0 \mathrm{~h}, p=229 \mathrm{hPa}$; (d) $t=+12 \mathrm{~h}, p=230 \mathrm{hPa}$. This makes evident two different categories of ISSRs: The first one, marked in blue is characterised by a weak ascent of all air parcels in the investigated column. The second one, marked in reddish colours, is more directly influenced by the outflow of the warm conveyor belt which results in a very strong ascent for at least one trajectory in the respective column. An intermediate category of maximum ascents (green colours) seems to be unimportant, at least in the situation investigated here.

below. In agreement to earlier results (Spichtinger et al., 2003a,b), but now from a different point of view, it could be shown that ISSRs only rarely reach into the lowermost stratosphere, and often the boundary of an ice supersaturated airmass closely coincides with the tropopause.

This case study has led us to a new perception of ice supersaturated regions. While our view was hitherto guided by one-dimensional cuts (MOZAIC flights, radiosonde ascents) through ISSRs and by statistical analyses of satellite data, the new visualisation presented in Figs. 8 and 9 together with the inspection of accompanying satellite imagery (METEOSAT, AVHRR) has furnished a much more complete picture. So far, we have considered ISSRs and cirrus distinct, albeit related, objects; hence we have considered ISSRs as cloud free. But the new perception of ISSRs is more comprehensive: ISSRs are the dynamic regions that we can see on Figs. 8 and 9, with a water vapour concentration exceeding ice saturation. Usually, an ISSR contains cirrus at some places while at other places it is clear. It still makes sense to contrast the properties of ISSRs within and without the clouds (Spichtinger et al., 2004), and also with the properties of air outside the ISSR; but it seems also to make sense to include the embedded cirrus clouds into the definition of ISSR. An essential difference between ice clouds and water clouds is that water clouds are congruent with their parent water supersaturated region while this is not so for ice clouds. An ISSR is not a closed system, there is always interaction with its surroundings. Air parcels that were outside the ISSR join it when they reach supersaturation, while at other locations parts of the ISSR vanish when the water vapour gets subsaturated. Parts of the ISSR get cloudy when there is enough cooling (updraught), while others remain clear. This new perception of ISSRs helps explain the strong similarity between spatial distributions of occurrence of ice supersaturation and (subvisible) cirrus clouds that we found in previous papers (e.g. Gierens et al., 2000; Spichtinger et al., 2003b). 


\section{Appendix A: Radiative transfer calculations}

For the radiative transfer calculation in Sect. 4.2 we assume that a cloud is a homogeneous layer (thickness $\Delta z$ ) with optical depth $\tau$ for monochromatic infrared radiation $(\lambda \approx 11.5 \mu \mathrm{m})$. Additionally, the cloud and the surface are assumed to be black bodies with mean temperature $T_{\text {cloud }}$ and $T_{\text {surf }}$, respectively. The absorption by air is neglected. Due to the inclined view of the satellite through the cloud layers the factor $\mu=\cos (\varphi)\left(\varphi\right.$ denotes latitude, here $\left.\varphi \approx 52^{\circ}\right)$ has been introduced for calculating the true "vertical" optical depth. Then we can set up the following equation for the radiances at satellite $\left(I_{\text {sat }}\right)$ and surface $\left(I_{\text {surf }}=B_{\lambda}\left(T_{\text {surf }}\right)\right)$ :

$I_{\text {sat }}=B_{\lambda}\left(T_{\text {surf }}\right) \cdot e^{-\frac{\tau}{\mu}}+B_{\lambda}\left(T_{\text {cloud }}\right) \cdot\left(1-e^{-\frac{\tau}{\mu}}\right)$,

where $B_{\lambda}(T)$ denotes the black body radiance at wavelength $\lambda$. Defining the brightness temperature $T_{\text {sat }}$ via $I_{\text {sat }}=B_{\lambda}\left(T_{\text {sat }}\right)$ we can calculate the optical depth $\tau$ :

$\tau=\log \left(\frac{B_{\lambda}\left(T_{\text {surf }}\right)-B_{\lambda}\left(T_{\text {cloud }}\right)}{B_{\lambda}\left(T_{\text {sat }}\right)-B_{\lambda}\left(T_{\text {cloud }}\right)}\right) \cdot \mu$.

The IWC of a homogeneous cirrus cloud with vertical thickness $\Delta z$ can be calculated from the (infrared) optical depth $\tau$ (Ebert and Curry, 1992):

$\tau=\beta \cdot \kappa_{i} \cdot$ IWP,

where $\beta=1.66$ is the diffusivity factor, $\kappa_{i}$ the mass absorption coefficient and IWP the ice water path, respectively. $\kappa_{i}$ in turn depends on the effective ice crystal radius, $r_{\text {eff }}$ (Curry and Herman, 1985):

$\kappa_{i}=\alpha_{i}+\frac{\gamma_{i}}{r_{\mathrm{eff}}}$,

with constants $\alpha_{i}$ and $\gamma_{i}$ (depending on the wavelength). If we additionally assume a constant IWC inside the (homogeneous) cloud the expression for the ice water path becomes very simple. Combining the above equations we get:

$\mathrm{IWC}=\frac{\tau}{\beta \cdot \Delta z \cdot\left(\alpha_{i}+\frac{\gamma_{i}}{r_{\mathrm{eff}}}\right)}$.

\section{Appendix B: Thermodynamic calculations}

For calculation of the contributions of the variables $T, q, p$ to the change of $R H i$ in Sect. 4.3.2 we start with the total differential

$d R H i=\frac{\partial R H i}{\partial T} d T+\frac{\partial R H i}{\partial q} d q+\frac{\partial R H i}{\partial p} d p$.

Using Eq. (2), the partial derivatives become:

$$
\begin{aligned}
\frac{\partial R H i}{\partial T} & =-100 \% \cdot \frac{p q}{\epsilon e_{\mathrm{si}}(T)^{2}} \cdot \frac{\partial e_{\mathrm{si}}(T)}{\partial T}, \\
\frac{\partial R H i}{\partial q} & =100 \% \cdot \frac{p}{\epsilon e_{\mathrm{si}}(T)}, \\
\frac{\partial R H i}{\partial p} & =100 \% \cdot \frac{q}{\epsilon e_{\mathrm{si}}(T)} .
\end{aligned}
$$

The partial derivative $\partial e_{\mathrm{si}}(T) / \partial T$ can be computed using the Clausius-Clapeyron equation and making some assumptions (e.g. the specific volume of water vapour $\alpha_{v}$ is much larger than that of ice $\alpha_{i}$; water vapour behaves as ideal gas under usual atmospheric conditions):

$\frac{d e_{\mathrm{si}}(T)}{d T}=\frac{L}{T\left(\alpha_{v}-\alpha_{i}\right)} \approx \frac{L}{T \alpha_{v}}=\frac{L e_{\mathrm{si}}(T)}{R_{v} T^{2}}$,

where $L$ denotes the latent heat for sublimation of ice (assumed to be constant). Therefore the total differential can be written as

$d R H i=-\frac{L R H i}{R_{v} T^{2}} d T+\frac{R H i}{q} d q+\frac{R H i}{p} d p$.

If changes $\delta T, \delta q, \delta p$ between two subsequent times steps are small enough, this equation can be used to determine the contributions $-\frac{L R H i}{R_{v} T^{2}} \delta T, \frac{R H i}{q} \delta q$ and $\frac{R H i}{p} d p$ of the distinct variables $T, q, p$ to the change of $R H i$, respectively. For easier comparison we normalise the contributions:

$\frac{-\frac{L R H i}{R_{v} T^{2}} \delta T}{\delta R H i}, \frac{\frac{R H i}{q} \delta q}{\delta R H i}, \quad \frac{\frac{R H i}{p} d p}{\delta R H i}$.

In our case this linearisation always accounts for more than 95\% of the change in $\mathrm{RHi}$ between subsequent time steps.

Acknowledgements. We thank R. Meyer and R. Büll for processing and providing the METEOSAT data and A. Dörnbrack for providing the ECMWF analyses. This article contributes to COST action 723 (Data exploitation and modeling for the upper tropopshere and lower stratosphere) and to the DLR/HGF-project "Particles and Cirrus Clouds" (PAZI-2).

Edited by: W. Lahoz

\section{References}

Curry, J. A. and Herman, G. F.: Infrared radiative properties of Arctic stratus clouds, J. Clim. Appl. Met., 24, 525-538, 1985.

Dowling, D. R. and Radke, L. F.: A summary of the physical properties of cirrus clouds, J. Appl. Meteorol. 29, 970-978, 1990.

Ebert, E. E. and Curry, J. A.: A parameterization of cirrus cloud optical properties for climate models, J. Geophys. Res., 97, 38313836, 1992.

Eckhardt, S., Stohl, A., Wernli, H., James, P., Forster, C., and Spichtinger, N.: A 15-year climatology of warm conveyor belts, J. Clim., 17, 218-237, 2004.

Gayet, J.-F., Crépel, O., Fournol, J. F., and Oshchepkov, S.: A new airborne polar Nephelometer for the measurement of optical and microphysical cloud properties. Part I: Theoretical design, Ann. Geophys., 15, 451-459, 1997 ,

SRef-ID: 1432-0576/ag/1997-15-451

Gierens, K. and Spichtinger, P.: On the size distribution of icesupersaturated regions in the upper troposphere and the lower stratosphere, Ann. Geophys., 18, 499-504, 2000,

SRef-ID: 1432-0576/ag/2000-18-499. 
Gierens, K., Schumann, U., Helten, M., Smit, H. G. J., and Marenco, A.: A distribution law for relative humidity in the upper troposphere and lower stratosphere derived from three years of MOZAIC measurements, Ann. Geophys., 17, 1218-1226, 1999 ,

\section{SRef-ID: 1432-0576/ag/1999-17-1218.}

Gierens, K., Schumann, U., Helten, M., Smit, H., and Wang, P.-H.: Ice-supersaturated regions and subvisible cirrus in the northern midlatitude upper troposphere, J. Geophys. Res., 105, $22743-$ $22753,2000$.

Gierens, K., Kohlhepp, R., Spichtinger, P., and SchroedterHomscheidt, M.: Ice supersaturation as seen from TOVS, Atmos. Chem. Phys., 4, 539-547, 2004,

SRef-ID: 1680-7324/acp/2004-4-539.

Heymsfield, A. J. and Miloshevich, L. M.: Homogeneous ice nucleation and supercooled liquid water in orographic wave clouds, J. Atmos. Sci., 50, 2335-2353, 1993.

Hoinka, K. P.: Statistics of the global tropopause pressure, Mon. Weather Rev., 126, 3303-3325, 1998.

Jakob, C., Andersson, E., Beljaars, A., Buizza, R., Fisher, M., Gérard, E., Ghelli, A., Janssen, P., Kelly, G., McNally, A. P., Miller, M., Simmons, A., Teixeira, J., and Viterbo, P.: The IFS cycle CY21r4 made operational in October 1999, ECMWF Newsletter, 87, 2-9, 2000.

Koop, T., Luo, B., Tsias, A., and Peter, T.: Water activity as the determinant for homogeneous ice nucleation in aqueous solutions, Nature, 406, 611-614, 2000.

Marenco, A., Thouret, V., Nedelec, P., Smit, H., Helten, M., Kley, D., Karcher, F., Simon, P., Law, K., Pyle, J., Poschmann, G., von Wrede, R., Hume, C. and Cook, T.: Measurement of ozone and water vapor by Airbus in-service aircraft: The MOZAIC airborne program, an overview, J. Geophys. Res., 103, 25 631-25 642, 1998.

Nagel, D., Leiterer, U., Dier, H., Kats, A., Reichard, J., and Behrendt, A.: High accuracy humidity measurements using the standardized frequency method with a research upper-air sounding system, Meteorol. Z., 10, 395-405, 2001.

Ovarlez, J. and van Velthoven, P.: Comparison of water vapour measurements with data retrieved from ECMWF analyses during the POLINAT experiment, J. Appl. Meteorol., 36, 1329-1335, 1997.
Ovarlez, J., van Velthoven, P., Sachse, G., Vay, S., Schlager, H., and Ovarlez, H.: Comparison of water vapor measurements from POLINAT 2 with ECMWF analyses in high humidity conditions, J. Geophys. Res., 105, 3737-3744, 2000.

Ovarlez, J., Gayet, J.-F., Gierens, K., Ström, J., Ovarlez, H., Auriol, F., Busen, R., and Schumann, U.: Water vapor measurements inside cirrus clouds in Northern and Southern Hemispheres during INCA, Geophys. Res. Lett., 29, doi:10.1029/2001GL014440, 2002.

Schumann, U.: Contrail Cirrus. In: Lynch, D. K., Sassen, K., Starr, D. O'C., and Stephens, G.: Cirrus, Oxford University press, Oxford, UK, 231-255, 2002.

Shapiro, M. A. and Keyser, D.: Fronts, jet streams and the tropopause, in: Extratropical cyclones, edited by: Newton, C. and Holopainen, E. O., The Erik Palmen Memorial Volume, Am. Meteorol. Soc., Boston, US, 167-191, 1990.

Spichtinger, P., Gierens, K., and Read, W.: The statistical distribution law of relative humidity in the global tropopause region, Meteorol. Z., 11, 83-88, 2002.

Spichtinger, P., Gierens, K., Leiterer, U., and Dier, H.: Ice supersaturation in the tropopause region over Lindenberg, Germany, Meteorol. Z., 12, 143-156, 2003a.

Spichtinger, P., Gierens, K., and Read, W.: The global distribution of ice-supersaturated regions as seen by the microwave limb sounder, Q. J. Roy. Meteorol. Soc., 129, 3391-3410, 2003b.

Spichtinger, P., Gierens, K., Smit, H. G. J., Ovarlez, J., and Gayet, J.-F.: On the distribution of relative humidity in cirrus clouds, Atmos. Chem. Phys., 4, 639-647, 2004,

SRef-ID: 1680-7324/acp/2004-4-639.

Wernli, H.: A Lagrangian-based analysis of extratropical cyclones. II: A detailed case study, Q. J. Roy. Meteorol. Soc., 123, 16771706, 1997.

Wernli, H. and Davies, H. C.: A Lagrangian-based analysis of extratropical cyclones. I: The method and some applications, Q. J. Roy. Meteorol. Soc., 123, 467-489, 1997.

Young, K. C.: Microphysical Processes in Clouds, Oxford University Press, Oxford, UK, xv + 427, 1993.

Young, M. V., Monk, G. A., and Browning, K. A.: Interpretation of satellite imagery of a rapidly deepening cyclone, Q. J. Roy. Meteorol. Soc., 113, 1089-1115, 1987. 